\title{
EDUCAÇÃO DO CAMPO ROMPE COM OS PARADIGMAS CONSERVADORES DA FORMAÇÃO DE PROFESSORES/AS
}

\author{
Rural Education breaches with the conservative paradigms of teacher training
}

\section{La Educación de los incumplimientos de Campo con los paradigmas conservadores de la formación de profesores}

Heloisa da Silva Borges*

\begin{abstract}
Resumo
Este texto é resultado dos estudos de pesquisa realizados no Programa de Pós-Graduação em Educação, com objetivo de subsidiar a Linha de Pesquisa: Formação e Práxis do/a Educador/a Frente aos Desafios Amazônicos. Teve os seguintes objetivos específicos: 1) Estudar os paradigmas conservadores que sustentam a formação de professores/as na sociedade capitalista; 2) Investigar como a Educação do Campo rompe com os paradigmas conservadores, especialmente na formação de professores/as. A metodologia adotada deu-se em dois momentos: pesquisa bibliográfica e documental. Mas para facilitar o estudo elaboramos duas questões norteadoras: 1) Quais são os paradigmas conservadores que sustentam a formação de professores/as na sociedade capitalista? e 2) Por que a Educação do Campo rompe com os paradigmas conservadores, especialmente na formação de professores/as? Assim, conclui-se que a formação de professores/as do campo, que se sustentam nos referenciais teóricos da pedagogia crítica não dialoga com a formação de professores/as ligadas aos paradigmas conservadores liberais e neoliberais, pois ambos possuem projetos de sociedade diferentes.
\end{abstract}

PALAVRAS - CHAVE: Educação do Campo. Paradigmas conservadores. Formação de professores/as.

\begin{abstract}
This text is the result of research studies carried out in the Graduate Program in Education, with the objective of subsidizing the Research Line: Education and Praxis of the Educator in the face

\footnotetext{
* Graduada em Pedagogia (FACED/UFAM), Especialista em Educação de Jovens e Adultos (FACED/UFAM), Mestrado em Educação pelo PPGE da FACED/UFAM. Professora do Departamento de Administração e Planejamento e do Programa de Pós-Graduação em Educação da Faculdade de Educação, da Universidade Federal Amazonas. Atualmente coordena o Parfor-UFAM- Universidade Federal do Amazonas, Faculdade de Educação. Endereço: Av. General Rodrigo, Octávio, 6200, Coroado I, 69000000 - Manaus, AM - Brasil. Contato: (092) 33051181. E-mail: helo-borges@ hotmail.com. Orcid: https://orcid.org/0000-0001-7629-7056
}

Educação e Fronteiras On-Line, Dourados/MS, | v. 10, n. 30,| p. 136-152,| set /dez 2020 
of Amazonian Challenges. It had the following specific objectives: 1) To study the conservative paradigms that support the training of teachers in the capitalist society; 2) To investigate how Rural Education breaks with the conservative paradigms, especially in the case of teacher education. The adopted methodology was of two types: bibliographical and documentary research. But to facilitate the study, we elaborated two guiding questions: 1) What are the conservative paradigms that support the formation of teachers in the capitalist society? and 2) Why does Rural Education break with the conservative paradigms, especially in the case of teacher education? Thus, it is concluded that the training of teachers in the rural areas, which is based on the theoretical frameworks of critical pedagogy does not dialogue with the training of teachers linked to the conservative liberal and neoliberal paradigms, as both have different projects of society.

KEYWORDS: Rural Education. Conservative paradigms. Teacher training.

\section{Resumen}

Este texto es el resultado de estudios de investigación realizados en el Programa de Posgrado en Educación, con el objetivo de subsidiar la Línea de Investigación: Educación y Praxis del Educador ante los desafíos amazónicos. Tenía los siguientes objetivos específicos: 1) Estudiar los paradigmas conservadores que apoyan la formación de docentes en la sociedad capitalista; 2) Investigar cómo la Educación Rural rompe con los paradigmas conservadores, especialmente en la formación docente. La metodología adoptada tuvo lugar en dos momentos: investigación bibliográfica y documental. Pero para facilitar el estudio, elaboramos dos preguntas orientadoras: 1) ¿Cuáles son los paradigmas conservadores que apoyan la formación docente en la sociedad capitalista? y 2) ¿Por qué la educación rural rompe los paradigmas conservadores, especialmente en la formación docente? Por lo tanto, se concluye que la formación de los docentes en el campo, que se fundamentan en los marcos teóricos de la pedagogía crítica, no dialoga con la formación de los docentes vinculados a los paradigmas conservadores liberales y neoliberales, ya que ambos tienen diferentes proyectos sociales.

PALABRAS CLAVE: Educación Rural. Paradigmas conservadores. Formación del profesorado.

\section{INTRODUÇÃO}

Este texto faz parte de estudos realizados no Programa de Pós-Graduação em Educação da Universidade Federal do Amazonas (UFAM), na Linha 3 - Formação e Práxis do(a) Educador(a) Frente aos Desafios Amazônicos. Compreendemos que os estudos são poucos sobre as categorias: Educação do Campo e Formação de Professores/as no Amazonas. Entretanto, ambas estão incluídas numa pluralidade de situações, que sustentam ações dos Movimentos Sociais, das políticas públicas de governos, que são os programas e dos próprios sujeitos envolvidos no processo formativo.

A pesquisa deu-se através de estudos bibliográficos, documentais de campo. Mas, nesse texto iremos tratar da abordagem bibliográfica e documental. Na pesquisa bibliográfica o estudo teve os seguintes autores: Alves Melo Júnior e Caiado (2018);

Educação e Fronteiras On-Line, Dourados/MS, | v. 10, n. 30,| p. 136-152,| set /dez 2020 
Borges (2015 /2016); Caldart (2004 / 2015 / 2017); Freitas (2018); Frigotto (2016); Luckesi (2017); Molina (2017); Moreira (2014); Peroni, Lima, Kader (2018); Saviani (2018); Silva (2013); SILVEIRA, SANTOS \& CHRISPINO (2019); Troquez. (2019).

A pesquisa documental utilizou-se dos seguintes documentos: Leis de Reformas №5.692/71 e Reformas N5.540/68 Constituição Federal de 1988; LDB N 9.394/96; Documentos das Conferências e Seminários Nacionais da Educação do Campo; Resolução $N^{\circ}$ 1, de 3 de abril de 2002, Diretrizes Operacionais para a Educação Básica nas Escolas do Campo, etc.

Para iniciar a elaboração do referido texto fizemos os seguintes questionamentos: 1) Quais são os paradigmas conservadores que sustentam a formação de professores/as na sociedade capitalista? 2) Por que a Educação do Campo rompe com os paradigmas conservadores, especialmente na formação de professores/as? Diante das duas questões vamos dar prosseguimento ao texto.

\section{A formação de professores/as e os paradigmas liberais e neoliberais}

A Formação de Professores/as do Campo não pode ter como base os paradigmas da Pedagogia Liberal ${ }^{1}$ e Neoliberal, entretanto, o texto tem foco somente em duas: a Tradicional, a Tecnicista e Qualidade Total (Pedagogia da Competência), por serem concepções que têm como pressupostos o liberal clássico ${ }^{2}$, visto que estimulam a liberdade e as diferenças individuais na sociedade, estabelecem organização social baseada na propriedade privada dos meios de produção. Além disso, essas Pedagogias definem e consideram que o ser humano é um ser livre, dotado de razão e cujo destino é vir a ser plenamente livre, para vender ou comprar sua força de trabalho. Fomentam a liberdade individualizada escondendo as diferenças sociais, pois quando enfatiza o indivíduo, passando a responsabilidade do sucesso, ou na maioria das vezes, o fracasso para a própria pessoa, uma vez que o Estado, nessa concepção, oferece condições e oportunidades para todos, embora não garanta as condições para que todos tenham acesso.

Luckesi (2017) diz que a pedagogia liberal alimenta a ideia de que a escola é a responsável pela formação das pessoas na sociedade. De tal modo, que somente os que tiverem acesso a ela serão preparados para desempenharem seus papéis sociais. Nessa lógica, podemos dizer que para os liberais a escola é um espaço de preparação aos valores e normas na conexão do mercado econômico da classe dominante, inclusive reforçando a individualidade e a competição entre as pessoas, sem pensarem numa possível mudança social, enquanto estrutura de classes. A ideia é da formação para o desenvolvimento de habilidades e para a veiculação dos valores éticos necessários à boa

\footnotetext{
${ }^{1}$ Segundo Luckesi (2017) e Libâneo (2019) as Pedagogias Liberais são: Tradicional, Pedagogia Renovada Progressivista, Pedagogia Renovada Não-Diretiva e Pedagogia Tecnicista.

${ }^{2}$ Corrente da economia do século XVIII e predominante no século XIX e XX, que representa as aspirações da burguesia de gerenciar seus próprios negócios, sem a intervenção do Estado.
}

Educação e Fronteiras On-Line, Dourados/MS, | v. 10, n. 30,| p. 136-152,| set /dez 2020 
convivência social.

Vale ressaltar que a Pedagogia Tradicional é a tendência mais usada na formação das pessoas no Brasil, muito presente no percurso formativo dos profissionais da educação. Inicialmente pela influência dos padres jesuítas, que trabalhavam para o ideário da formação de pessoas subserviente na sociedade (SAVIANI, 2018). Nessa tendência, a educação escolar reforça os laços sociais, promovendo a coesão social, para garantir a integração de todos os indivíduos na sociedade. Ela é doutrinária, porque prega uma visão de uma sociedade harmoniosa, perfeita e sem problemas. Nessa concepção, o/a professor/a é uma pessoa passiva socialmente, no entanto, num estilo autoritário, acrítico e incapaz de compreender e questionar os fatos sociais ao seu redor, tendo como foco o educar para preservar a ordem social.

Nessa Pedagogia Tradicional, o/a professor/a não ensina e sim repassa, de forma vertical, os conteúdos que são previamente estabelecidos nos livros, preparados aparentemente de forma neutra fazendo com que os estudantes tenham a compreensão de uma sociedade sem problemas na sua estrutura social, etc., reforçando a harmonia e as dimensões intelectuais e morais dos mesmos. Os educandos devem superar suas dificuldades, para conquistar seu lugar na sociedade. No campo intelectual, somente alguns podem desenvolver tais habilidades, e a maioria deve voltar-se para a área prática (trabalho manual). Sendo, de responsabilidade da escola a vigilância constante quanto à formação moral do educando, uma vez que se fundamenta na concepção de que o homem é mau e corruptível. A educação escolar disciplina o homem, através dos castigos corporais, para melhor internalizar a hierarquia social (SAVIANI, 2018).

A Pedagogia Tecnicista, é parte integrante da Pedagogia Liberal, tem como base o modelo empresarial, para atender às exigências da sociedade industrial e tecnológica, por isso sua ênfase é na preparação de mão de obra. Seu método tem por base os modelos taylorista e fordista, com ênfase nas tarefas e nas questões de ordem técnica como: livro didático, planejamento, reuniões, metas etc. Esses dois modelos de gerenciamento, pensados e desenvolvidos nas fábricas, foram, por muito tempo, utilizados no século $\mathrm{XX}$, tendo como centro a formação de pessoas sem a preocupação com o conhecimento mais elaborado e sim mecânico, com as devidas fragmentações da divisão social do trabalho. Essa tendência tem seu pressuposto teórico na filosofia positivista de Augusto Comte, orientada pela ideia de Estado positivo ${ }^{3}$, mas também na corrente behaviorista norte-americana, a partir da teoria do reforço positivo e negativo, relacionada ao comportamento operante de Skinner, e depois com Gagné, Bloom e Mager (BORGES, 2015).

A Pedagogia Tecnicista tem forte influência na Formação de Professores/as, em decorrência da Lei de Reforma do Ensino de $1^{\circ}$ e $2^{\circ}$ Graus $n^{\circ} 5.692 / 71$ e da Lei de Reforma Universitária $\mathrm{N}^{\circ} 5.540 / 68$, que se pautou no conhecimento técnico, o qual propunha o domínio do fazer de forma prática. Ao mesmo tempo, tanto os/as

\footnotetext{
${ }^{3}$ Estado positivo é aquele que o homem atinge depois de ter superado outras formas menos rigorosas de conhecer a realidade, até compreender que o conhecimento científico é o mais adequado para explicá-la. Educação e Fronteiras On-Line, Dourados/MS, | v. 10, n. 30,| p. 136-152,| set /dez 2020
} 
professores/as, quanto os estudantes são espectadores do processo de aprendizagem, não havendo a necessidade de debates, discussões, questionamentos, relações afetivas e pessoais. A aprendizagem é centrada no controle sobre o comportamento dos estudantes na busca da eficiência do mercado econômico.

Essa tendência, de origem americana, influenciou o Brasil, nos anos 50, através do PABAEE (Programa Brasileiro-Americano de Auxilio ao Ensino Elementar) (MOREIRA, 2014). Entretanto, é após o golpe militar de 1964 que se intensificou tal influência, através do acordo MEC-USAID, e das leis de reformas ${ }^{4}$ e a Lei 7.024/82 (que revoga o caráter compulsório do ensino profissionalizante), as quais vigoraram no país até a aprovação da segunda Lei de Diretrizes e Bases da Educação Nacional, $\mathrm{n}^{\mathbf{0}}$ 9.394/96.

Na Tendência Tecnicista, os/as professores/as são especialistas que executam seus planos, devidamente elaborados, sob a supervisão de alguém que controla o que vai ministrar durante as aulas. Os/as professores/as devem ser apáticos à realidade e desinteressados, utilizam os recursos tecnológicos e didáticos mecanicamente, não precisando pensar sobre seus trabalhos e sim executá-los para quantificar os resultados. Os/as professores/as de hoje ainda têm sua base epistemológica nesta formação, decorrente do antigo Curso de Magistério (2 ${ }^{\circ}$ Grau), Curso Normal Superior, Licenciatura em Pedagogia e as demais licenciaturas, que tinham como embasamento a tendência tecnicista.

O tecnicismo é sustentado e dirigido pela ideia de uma ciência administrativa que define o que deve ser feito, controla, supervisiona e avalia a atuação dos/as professores/as, sua formação não passa pelos aspectos morais, éticos e nem cognitivos por sua atuação ser baseada nas tarefas rotineiras relacionadas à padronização dos modelos impostos pelo sistema educacional, além de não permitir nenhum tipo de reflexão sobre o processo formativo ficando distante da sua própria realidade (SAVIANI, 2018).

As Tendências aqui apresentadas são as que mais marcaram a formação de professores/as no Brasil oficialmente. Muitos deles que atuam na sala de aula foram formados de acordo com essas duas tendências pedagógicas, reproduzindo um ensino totalmente técnico e reducionista, tendo assim dificuldades de pensar criticamente. $\mathrm{O}$ contexto histórico, econômico e político em que elas se encontravam sustentavam-se a partir da ideia de que a escola e a formação serviriam para atender à sociedade de classes, mas sem compreender o processo de exploração vivenciada por ela e sim numa relação de alienação social.

A formação de professores/as está associada às necessidades da estrutura social de classes, uma vez que são eles que educam as novas gerações, deixando de lado a realidade concreta da maioria da população, prevalecendo os ideais das classes

\footnotetext{
${ }^{4}$ Lei de Reforma Universitária, $\mathrm{n}^{\circ}$ 5.540/68 (formação do pedagogo e de professor de Licenciaturas curta ou plena) e a Lei de Reforma de $1^{\circ}$ e $2^{\circ}$ Graus, $n^{\circ} 5.692 / 71$ (cursos profissionalizantes, especial para professor(a) no magistério.

Educação e Fronteiras On-Line, Dourados/MS, | v. 10, n. 30,| p. 136-152,| set /dez 2020
} 
dominantes, que definem as necessidades que os meios de produção terão para produzir seus produtos e, ao mesmo tempo o que as populações deverão consumir no seu dia a dia, tendo como base, o princípio de que as formações são estabelecidas a partir de e para o mercado do capital (FRIGOTTO, 2016).

Como o capitalismo vive em constante crise, portanto, ele vai criando novas formas de organização na estrutura de sua base que são os meios de produção. Desta forma, outros paradigmas são recriados para atender a relação da base econômica do capital e seu processo de exploração (FRIGOTTO, 2016).

As mudanças atuais provocadas pela globalização da economia na sociedade contemporânea estão ligadas a vários aspectos da realidade política, tecnológica, cultural, social, ambiental e, sobretudo, da realidade educacional. São novas formas que intensificaram as relações entre os países através da integração dos mercados nacionais ao mercado internacional, permitindo a interdependência cultural e econômica (FREITAS, 2018).

Assim, as mudanças no processo econômico influenciam na construção de valores, ideias, visões, padrões de comportamento, hábitos, gostos, gêneros literários e musicais. Essa integração acontece através das novas tecnologias de informação, que permitem aos grandes capitais, por meio de sistemas de processamento e banco de dados, operar ininterruptamente por dia e cobrir o espaço econômico global, provocando a homogeneização das populações em realidades distintas.

A transformação na economia vem sendo acompanhada pelos organismos internacionais (ONU, Fundo Monetário Internacional, Banco Mundial etc.) e até mesmo dirigida por eles (PERONI, 2018). Essas alterações possibilitaram a expansão da política neoliberal propiciando as intervenções que passaram a ser realizadas através da ocupação dos espaços geográficos, onde as empresas instalam-se para montar ou vender seus produtos.

O neoliberalismo instalou-se não só pelo discurso hegemônico dos governos, mas também em função da utilização da incorporação massiva da ciência e da tecnologia (microeletrônica, biotecnologia, novos materiais etc.), como força produtiva direta. A única forma de legitimar a ordem social na sua atividade estrutural passa, mais do que nunca, pela educação para atender o mercado, que se apresenta como instância reguladora da moderna cidadania, pois o modelo hegemônico constrói-se e ajusta-se ao mercado.

Atualmente, numa lógica empresarial os governos vêm aplicando políticas de gestão nos sistemas de ensino da rede pública, com base na reestruturação produtiva tendo como centro a Pedagogia da Competência, que nada mais é senão a Gestão da Qualidade Total, associada às ações do neoliberalismo.

Segundo Freitas (2018. p 22):

Para o neoliberalismo, as garantias deveriam ser incluídas nas constituições nacionais de forma a se tornar praticamente irrevogáveis, mesmo por caminhos que pudessem significar uma ruptura com as teses da democracia

Educação e Fronteiras On-Line, Dourados/MS, | v. 10, n. 30,| p. 136-152,| set /dez 2020 
liberal. Afinal, o que está em jogo é a "liberdade pessoal e social" que precisa ser defendida a qualquer custo para deter a ideia de uma economia planificada (contraria ao livre mercado).

Frigotto (2016) argumenta que através da educação usada pelos homens de negócio, para supostamente resolver os problemas que existem na sociedade, na verdade são meras estratégias para atender os seus próprios interesses, uma vez que a nova base tecnológico-material do processo de produção se alterou para dar resposta à necessidade do mercado.

Portanto, o sistema educacional volta-se para uma educação básica, para uma formação abstrata e polivalente do ser humano, no qual seja capaz de pensar, de participar, de motivar e de enfrentar as dificuldades e de competir. Na verdade, trata-se de um aprendizado complexo, a ser exercitado não apenas nas escolas, mas na vida em geral. Um amplo processo participativo, restaurador do ser humano genérico, que envolve princípios, valores, utopias e, certamente, um contrato planetário, social e natural, no qual animais e homens/mulheres, natureza e cultura não se separem mais.

$\mathrm{Na}$ realidade, a ideia é da sociedade do conhecimento na lógica do capital. Por isso, esses paradigmas trabalham com metodologias clássicas fazendo com que a o conhecimento fragmentado das disciplinas, não corresponde à realidade das pessoas. Diante do exposto, consideramos que "é necessário repensar o saber disciplinar para além dos domínios da disciplina específica" (SILVEIRA, SANTOS \& CHRISPINO, 2019. p. 169), dialogando com a princípio com a interdisciplinaridade.

\section{Educação do Campo rompe com os paradigmas conservadores}

Diante do exposto, no subtópico anterior perceptível que a Educação do Campo não tem como se aproximar dos paradigmas conservadores sejam liberais ou neoliberais. Uma vez que, ela centra-se na perspectiva de transformação da sociedade, considerando que qualquer mudança não ocorre de cima para baixo, mas sim no sentido inverso. Também defende que é preciso fazer valer o direito de todos os sujeitos do campo, quanto ao acesso, de forma digna, à cidadania, independente do contexto. Sendo assim, com ou sem organização social, as políticas públicas devem existir, garantindo qualidade social referendada e o bem viver dos sujeitos do campo.

A Educação do Campo, em seu processo pedagógico, assume uma conotação política, a fim de garantir a intervenção da materialização da consciência crítica e ajudando na formação dos sujeitos, para que se tornem protagonistas de suas vidas, rompendo com a submissão e com o silêncio, que muitas vezes são presentes no modo de vida da população do campo. Logo, a formação desejada quebra com a reprodução cultural e social do poder vigente, fazendo com que os professores, professoras e comunitários sejam capazes de denunciar, discutir sobre seus problemas, suas causas e também dialoguem, no coletivo, buscando soluções e intervindo diretamente em sua realidade, enxergando-se além de seus olhos (2017). 
O processo formativo da Educação do Campo não tem identidade com a ordem social vigente, porque seus princípios filosóficos e pedagógicos trabalham na busca da transformação das relações de poder. Logo, é complexa, já que envolve a construção de um novo tipo de poder, rompendo com o paradigma do opressor e do oprimido tendo "[...] a ver com novos valores, novas relações entre as pessoas, homens e mulheres, adultos e crianças, dirigentes de base, novos posicionamentos diante das várias questões da vida. [...]" (CALDART, 2004. p. 7). Sendo assim, supera o comportamento individualista, autoritário, comodista, personalista etc., costumes e hábitos, que foram e são estimulados pelo modelo social na sociedade capitalista.

Ao constatarem que a formação oferecida pelo Estado aos sujeitos do campo não atendia às expectativas do mundo do trabalho do campo, os Movimentos Sociais do Campo dialogaram, procurando sentido para a ideia da formação de sujeitos do campo. Esses Movimentos são compostos por vários outros movimentos de cunho: religioso, sindical, popular, mulheres, quilombolas etc. Mas, a luta pela mobilização em defesa da escola e dos ideais fundamentais pedagógicos da Educação do Campo é antigo, oriunda da Educação Popular, destacando os seguintes movimentos e organizações: Educação Popular (MCP, CPC, Campanha de Pé no Chão também se aprende a ler, MEB); Ação Católica e Ação Popular (JAC, JEC, JIC, JOC e JUC); movimentos sociais do campo (Liga Camponesas, ULTRAB, MASTER) (SILVA. 2013. p. 38).

Apesar de vários movimentos sociais no campo, optamos em expor o que os une e os move seus valores, princípios, objetivos e práticas, sobretudo do MST e CONTAG. Principalmente por esses serem os principais Movimentos que vêm, ao longo de suas histórias, desenvolvendo experiências e reforçando a luta pelo direito a Educação Escolar. Entretanto, não é negado a contribuições de outros movimentos como: Movimento dos Atingidos por Barragens (MAB), da Rede de Educação do Semiárido Brasileiro (RESAB), do Centro Familiar de Formação por Alternância (Rede CEFFAS), etc.

Para compreender como se deu a constituição dos princípios presentes nas linhas de ações do coletivo dos Movimentos e de suas reivindicações através da luta pela Educação no Campo, elaboramos um quadro com os princípios filosóficos e pedagógicos que orientam as lutas pela Educação do Campo, a seguir.

Quadro - Princípios Filosóficos e Pedagógicos dos Movimentos

\begin{tabular}{|c|c|}
\hline MST $^{5}$ & MSTTR $^{6}$ \\
\hline
\end{tabular}

\footnotetext{
${ }^{5}$ Caderno de Educação no 8 - Princípios da Educação no MST (2004).

${ }^{6}$ Projeto Político Pedagógico do Movimento Sindical dos Trabalhadores e Trabalhadoras Rurais (MSTTR), movimento ligado a CONTAG.

Educação e Fronteiras On-Line, Dourados/MS, | v. 10, n. 30,| p. 136-152,| set /dez 2020
} 
- Educação de classe;

- Educação massiva;

- Educação organicamente vinculada ao Movimento Social;

- Educação aberta para o mundo;

- Educação para ação;

- Educação aberta para o novo;

- Relação entre prática e teoria;

- Combinação metodológica entre processos de ensino e de capacitação;

- A realidade como base da produção do conhecimento;

- Conteúdos formativos socialmente úteis;

- Educação para o trabalho e pelo trabalho;

- Vínculo orgânico entre processos educativos e processos políticos;

- Vínculo orgânico entre processos educativos e processos econômicos;

- Vínculo orgânico entre educação e cultura;

- Gestão democrática;

- Auto-organização dos/das estudantes;

- Criação de coletivos pedagógicos e formação permanente dos educadores/das educadoras;

- Atitude e habilidade de pesquisa
- A compreensão do ser humano em sua totalidade;

- A permanente abertura aos vários saberes;

- A reconstrução da mística de mudança social;

- Permanente articulação entre prática e teoria;

- Interdisciplinaridade na abordagem dos conhecimentos;

- Formação pluralista, classista, crítica e criativa;

- Formação numa perspectiva de ação transformadora;

- Postura avaliativa e crítica permanente da ação e da prática formativa;

- A pesquisa como princípio educativo;

- A construção coletiva do conhecimento;

- A vivência de relações horizontais entre educador e educadora, e educandos e educandas;

- Fortalecimento das identidades: respeito às diferenças de raça, etnia, geração, gênero e religião;

- A memória enquanto um potencial crítico-transformador na formação. Fonte: Tese Formação Contínua de Professores/as da Educação do Campo no Amazonas Ano: PPGE/UFAM (2015)

O quadro não apresenta divergências entre os princípios dos 2 (dois) movimentos, aparecem como se estivessem completando-se. Os princípios do MST expressam posição mais voltada para os aspectos: filosófico, social, cultural, econômico e pedagógico. Ambos expressam uma visão de mundo, contrapondo-se ao modelo de sociedade de classes que a sociedade brasileira vem vivendo historicamente. Reconhecendo a educação como espaço de luta e ações voltadas para intervenção para as transformações na estrutura social. Os princípios do MSTTR estão voltados para as questões mais pedagógicas e metodológicas do processo formativo, ou seja, os princípios voltam-se para a formação, tendo como centro a concepção de educação, garantindo o processo formativo dos sujeitos do campo, numa perspectiva transformadora também. O que fica evidenciado que os movimentos não concordam com a formação conservadora dos liberais e neoliberais que a sociedade brasileira vem tendo, em especial os sujeitos do campo.

Os princípios mencionados têm como referenciais, em seus diálogos, com o ser humano e o seu desenvolvimento. Entrelaçam-se e reforçam que a formação trabalhada Educação e Fronteiras On-Line, Dourados/MS, | v. 10, n. 30,| p. 136-152,| set /dez 2020 
nas escolas públicas do campo não corresponde aos seus princípios, que são resultados de longos estudos, discussões e debates nos próprios movimentos. Uma vez que foram conjunto de ações que geraram propostas, cujas pautas sustentaram a agenda da luta pela educação escolar na sua perspectiva da formação de seus membros, deixando evidente que os interesses dos governantes e das classes dominantes não são os mesmos dos sujeitos do campo.

Apesar das divergências internas entre eles, os Movimentos uniram-se e passaram a lutar pelo direito à Educação Escolar no e do campo, de maneira que os sujeitos do campo tenham acesso à escolarização nos seus espaços territoriais, voltandose para suas culturas. A exemplo, pode-se citar o Documento-síntese do Seminário da Articulação Nacional Por uma Educação Básica do Campo, de 1999, que reafirma a necessidade de práticas e posturas pedagógicas que superem os valores anti-humanos centrados no mercado do capital. Assim, os Movimentos Sociais do Campo (Via Campesina; MAB, MPA, ANMTR, CPT, PJR), retomam a discussão no Seminário Nacional "Por uma Educação do Campo", em Brasília, em 2002, com os seguintes princípios (aqui resumidos) que são:

1) O centro é o ser humano, com uma formação humanizadora plena, considerando que a educação e a escola são direitos das pessoas;

2) Contrapor à lógica de que escola de meio rural é escola pobre, ignorada e marginalizada, devendo aqueles que desejem estudar saírem do campo e sim estudar para viver no campo;

3) A luta para garantia que todas as pessoas do campo tenham acesso à educação pública e de qualidade, com estratégias especificas de acordo com sua realidade;

4) Novo modelo de agricultura para inclusão e não para excluir;

5) A luta pela escola no e do campo, que valorize a história, a cultura, o trabalho e as causas sociais e humanas dos sujeitos do campo;

6) Educação compreende todos os processos sociais de formação das pessoas como sujeitos de seu próprio destino;

7) Valorização profissional valorizando os educadores e educadoras do campo e efetive políticas educacionais, por meio de projeto educativo do povo que vive no campo;

8) Educação integral, que envolva as questões de gênero, de raça, de respeito às diferenças culturais e as diferentes gerações, a soberania alimentar, agricultura sustentável e de uma política energética que proteja o meio ambiente;

9) Os Movimentos Sociais devem ser os guardiões dos direitos público, tendo o Estado o dever de escutar e respeitar o povo do campo, com políticas públicas de fato;

10) O sujeito que vive no campo deve ser protagonista de sua própria formação;

Educação e Fronteiras On-Line, Dourados/MS, | v. 10, n. 30,| p. 136-152,| set /dez 2020 
11) Educação como instrumento de participação democrática de forma dialógica e de luta pela justiça social e pela emancipação humana;

12) Reconhecem os avanços com atual LDB, as Diretrizes Nacionais e as Diretrizes Operacionais para as Escolas do Campo;

13) Consolidação das organizações que trabalham pela causa.

14)

Esses princípios, pautados e revalidados pelos Movimentos Sociais do Campo nas Conferências, nos Seminários e no Fórum Nacional de Educação do Campo, evidenciam que a Educação do Campo necessita de uma escola que seja um espaço que os sujeitos do campo estudem para viver no campo e que as crianças, adolescentes, jovens, adultos e idosos possam sentir orgulho de sua origem e de sua própria identidade. Por isso, os processos formativos da escola pública do campo precisam ser amplos, que tenha uma relação com contexto social, cultural, econômico, etc., do campo, ou seja, com o trabalho e a terra. (CALDART, 2015).

Porque, segundo Caldart (2015, p. 27):

A concepção que ainda é dominante em nossa sociedade é reducionista, vendo a educação com função propedêutica, transmissiva, utilitarista, como uma "preparação para a vida", que cada vez mais se reduz a uma preparação para competição no mercado: é preciso competir para ser explorado pelo capital, pois, um confronto fundamental de matriz formativa que precisam ser enfrentado.

Diante das questões apresentadas, pode-se dizer que as políticas públicas da Educação do Campo, muitas vezes, sustentam apenas aquela denominação, uma vez que existe uma lacuna no domínio das dimensões que compõe a Educação do Campo em sua essência, em relação aos aspectos: político, pedagógico e epistemológico. Estes pontos, uma vez não dominados no processo de formação dos sujeitos do campo, por mais boa vontade que se tenha para viabilizar o acesso à Educação do Campo, levará apenas à Escola do Campo, com metodologias talvez um pouco mais ousadas.

Essa estratégia de institucionalizar a Educação do Campo como uma política pública no país, significa um avanço para a população do campo, tais como os ribeirinhos, assentados, colonos, descendentes de escravos nos quilombolas, indígenas, etc. (BORGES, 2015). Nos últimos anos foram várias as normatizações, com resoluções e implementação de vários programas ligados diretamente as ações do governo federal, que proporcionaram as ações dos governos estaduais e municipais em relação às políticas da educação aos sujeitos do campo. Entretanto, apesar das ações promovidas pelos governos federais no período de 2004 a 2016, não podemos dizer que exista uma política pública de estado para este segmento e sim ações meramente de governos (PERRONI, 2018).

Nesse sentido, a formação de professores/as que atuam nas escolas do campo, foi atendida pelos seguintes programas como é possível observar na Figura: 


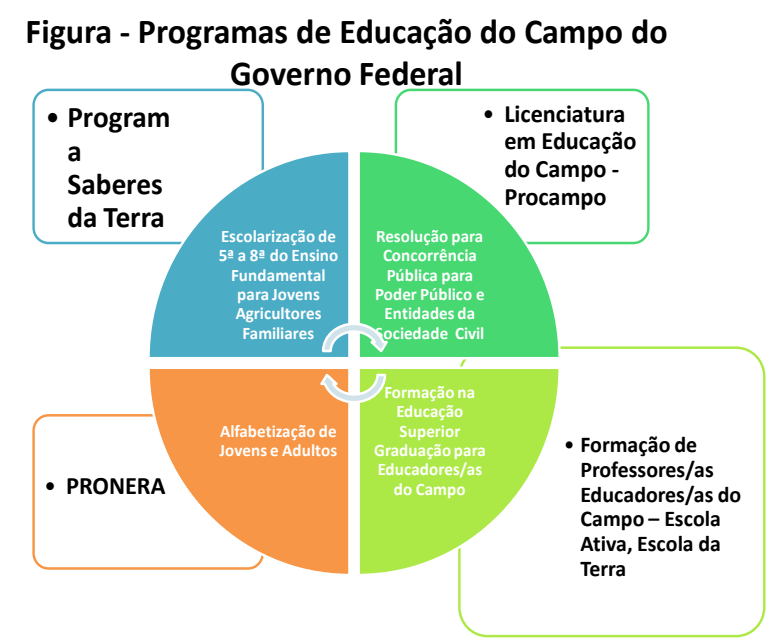

Fonte: Tese Formação Contínua de Professores/as da Educação do Campo no Amazonas Ano: PPGE/UFAM (2015)

Podemos dizer que houve o avanço da conquista pela garantia da identidade, com base nas questões da realidade do campo e na busca de assegurar aquela natureza de cultura, conforme a temporalidade dos saberes próprios dos sujeitos, de suas memórias, dando-lhes qualidade social e coletiva a vida no campo. Este progresso, presente na lei, entra em contradições com a LDB $\mathrm{n}^{\circ}$ 9.394/96, quando trata da Formação de Professores(as), uma vez que LDB estabelece, nos artigos 12, 13, 16 e 62, a exigência do docente para atuar na docência a formação no ensino superior, em cursos de licenciaturas. Portanto, o art. $2^{\circ}$ fere a LDB, as Resoluções ${ }^{7}$ e Pareceres, que também tratam da Formação de Professore (as) da Educação Básica e fazem a exigência da formação em curso superior.

Mas a Resolução das Diretrizes Operacionais, no art. 12, ressalta que a Formação de Professor/a do Campo, em nível de ensino superior, porém, a questão é que predomina o nível médio, como podemos constar: "[...] Formação em Curso de Nível Médio, na modalidade de Normal". Ou seja, a Lei sinaliza para a necessidade de cursos de licenciaturas voltados para a realidade do campo, entretanto, deixa o espaço aberto em relação à formação de professores/as, podendo ser o mesmo que é oferecido nos cursos regulares de nível médio. É bem verdade que os cursos de magistério em nível médio, no formato do antigo $2^{\circ}$ grau, com a atual LDB tornam-se inexistentes. Entretanto, a própria lei assegura o Curso Normal para atender o processo de Formação de Professores/as no Campo.

A Resolução $\mathrm{N}^{\circ}$ 01, de 3 de abril de 2002 - Diretrizes Operacionais para a Educação Básica nas Escolas do Campo, no art. 13, faz referência aos sistemas de ensino para as orientações das escolas do campo. Normatiza a Formação de Professor (a), para o exercício da docência nas escolas do campo, com os seguintes incisos:

\footnotetext{
7 3/1997; 2/1999; 1/2002 e 2/2002.

Educação e Fronteiras On-Line, Dourados/MS, | v. 10, n. 30,| p. 136-152,| set /dez 2020
} 
I - estudos a respeito da diversidade e o efetivo protagonismo das crianças, dos jovens e dos adultos do campo na construção da qualidade social da vida individual e coletiva, da região, do país e do mundo;

II - propostas pedagógicas que valorizem, na organização do ensino, a diversidade cultural e os processos de interação e transformação do campo, a gestão democrática, o acesso ao avanço cientifico e tecnológico e respectivas contribuições para a melhoria das condições de vida e a fidelidade aos princípios éticos que norteiam a convivência solidária e colaborativa nas escolas democráticas.

Considerando que os incisos da normatização reforçam a necessidade de formação dos sujeitos do campo, na perspectiva dos princípios dos movimentos sociais, é possível dizer que existe a necessidade real de formação dos professores/as, que não são nos moldes dos paradigmas liberais ou neoliberal, que historicamente vinha ocorrendo (SAVIANI, 2018). Desta forma, os referidos incisos citados acima devem orientar os possíveis cursos de Formação de Professores/as do Campo, que significa uma conquista, apesar dos dois artigos (12 e 13) anteriores darem ênfase a formação em nível médio. Do ponto de vista legal, esta Resolução é a primeira que traz a preocupação da necessidade da Formação do Professor do Campo de forma diferenciada, já no viés da perspectiva da Educação do Campo.

Mas, também podemos citar que a política de formação de professores/as do campo é contrária à lógica da escola do capital. Pois segundo Molina (2017), a base da matriz formativa da Educação do Campo é o princípio da formação humana, rejeitando a matriz da escola capitalista, cuja lógica estruturante é a produção de mão de obra para o mercado. Por isso, a formação dos professores/as que desenvolverem a competência, o intelecto dos sujeitos, trabalhar a formação de valores, o desenvolvimento político, ético, estético e corpóreo.

Para Molina (2017. p 591), os cursos de formação de professores/as têm contribuído com os seguintes pontos:

- a redefinição das funções sociais da escola, base da matriz formativa da LEdoC;

- uma matriz ampliada de formação, que parte das especificidades dos sujeitos a educar;

- a ressignificação da relação entre Educação Básica e educação superior, e entre formação inicial e continuada;

- a relação entre teoria e prática que orienta a matriz formativa dessas Licenciaturas.

Assim, podemos dizer que é relevante a formação dos professores/as das escolas do campo, numa perspectiva da Pedagogia Critica, que seja capaz de construir, disputar e de lutar por um novo projeto de sociedade, aonde o campo rompa com os paradigmas conservadores liberais e neoliberais, do modelo agrícola do latifúndio e compreenda a necessidade da "desterritorialização dos camponeses, promovendo uma intensa fagocitose de suas terras, de seu trabalho, de suas comunidades, de sua cultura, de suas escolas" (MOLINA, 2017. p. 593).

Educação e Fronteiras On-Line, Dourados/MS, | v. 10, n. 30,| p. 136-152,| set /dez 2020 
A Educação do Campo tem como pressupostos teóricos com base na Pedagogia Crítica, especialmente nas Pedagogias: Socialista Soviética; Educação Popular/Pedagogia do Oprimido de Paulo Freire; a Pedagogia do Movimento (BORGES, 2016). Todas elas servem como base para as lutas dos Movimentos Sociais do Campo, por uma educação diferenciada, crítica, transformadora e emancipadora; numa dimensão dialética voltada para a formação política, ideológica, organizativa, técnica, moral, cultural e estética. Assim ocorre porque se entende que é através da educação que ocorre o processo formativo dos sujeitos inseridos numa determinada sociedade, ou grupo, transformando-se e transformando-a.

Pois, segundo Alves, Melo Júnior e Caiado (2018) os conhecimentos acumulados pela humanidade ao serem estudados pelos estudantes do campo, na perspectiva emancipadora darão força intelectual para capacitá-los para luta, para vida e para suas atividades culturais em resistência ao capitalismo. Uma vez que a educação é uma atividade procuradora da prática social. Sendo uma caminhada tendo a própria prática educativa como inicio e à prática social como a chegada.

Apesar, de avanços no processo formativos dos/as professores/as e dos educandos do campo ainda encontramos muitas resistências ao reconhecer que a educação, é um direito de todos e que as propostas curriculares são verdadeiras arenas. Porque são elas que conduzem o processo formativo dos sujeitos. Ao entender isso, a luta pelo espaço formativo é uma reivindicação natural dos movimentos sociais do campo, para ter assegurado a "inclusão das culturas, línguas e identidades indígenas no currículo como elementos articuladores centrais da seleção, organização e distribuição do conhecimento, ou seja, de todo o processo de escolarização" (TROQUEZ, 2019. p. 211). Assim, pode-se dizer que a Educação do Campo é um projeto político de sociedade numa dimensão de mundo, que se contrapõe às contradições impostas na sociedade vigente.

\section{CONSIDERAÇÕES FINAIS}

A luta no campo pela posse da terra é muito antiga, antecede a luta pela Educação do Campo. A Educação do Campo entra em pauta, quando os Movimentos Sociais do Campo, principalmente o MST, passam a discutir a luta pela terra, deixando de lado a visão ingênua de que a posse dela seria simplesmente o objetivo final para sua cidadania. É quando percebem que a luta pela Educação do Campo amplia não só a possibilidade de ter cidadania na lógica liberal, mas contribui para que se reconheça que o exercício da cidadania liberta da condição de oprimido e explorado. Entretanto, a Educação do Campo, na condição de política pública, abre caminho para a construção da emancipação social. A partir desse entendimento, as lutas pela garantia legal de políticas públicas, em particular a escolarização, presentes no campo, tornou-se um dos centros da pauta reivindicadora dos Movimentos Sociais do Campo.

Desta forma, reafirmamos que a Educação do Campo é resultado dos fundamentos ligados a Pedagogia Crítica, em que os Movimentos Sociais do Campo se apoiam para lutar e reivindicar políticas públicas como: saúde, moradia, educação etc. Por isso, a necessidade da organização dos sujeitos do campo, para superarem o Educação e Fronteiras On-Line, Dourados/MS, | v. 10, n. 30,| p. 136-152,| set /dez 2020 
paradigma que atendem aos interesses dos parâmetros do mundo do trabalho do capitalismo. Sendo assim, ao longo da história, os sujeitos do campo ficaram fora das prioridades relacionadas às políticas públicas, uma vez que o Estado na sociedade de classes atende ao que considera fundamental para o desenvolvimento dos donos dos meios de produção, consequentemente do trabalho assalariado, dando ênfase à formação para atender ao mercado de trabalho.

Diante do exposto, podemos concluir que os paradigmas conservadores: liberal e neoliberal, não possuem condições de ser à base do processo formativo da Educação do Campo, principalmente em relação à Formação de Professores/as, por não serem capazes de emancipar, e sim de manter a estrutura da sociedade vigente, uma vez que negam toda essência teórica e prática da Educação do Campo, fugindo dos princípios, dos valores, dos objetivos propostos na formação dos sujeitos do Campo.

\section{REFERÊNCIAS}

ALVES, Jackeline Silva. MELO JÚNIOR, Arlindo Lins de. CAIADO, Kátia Regina Moreno. Um Olhar sobre as Políticas Públicas da Educação do Campo e Educação Especial à Luz da Pedagogia Histórico-Crítica. Revista Educação e Fronteiras On-Line. Dossiê Direito à Educação: da previsão à concretização. Dourados/MS. v. 8, n. 23, 2018.

BORGES. Heloisa da Silva Borges. Formação contínua de formação de professores/as da educação do campo. Manaus-AM. PPGE-UFAM, 2015.

Heloisa da Silva Borges. As Teorias que Legitimam a Educação do Campo. Boa Vista-RR. (ORG.) GHEDIN, Evandro. Fundamentos filosóficos a Educação do Campo. Editora da UFRR, 2016.

BRASIL. Constituição federal de 1988.

Lei de diretrizes e bases da educação brasileira LDB No 9.394/96.

. Resolução $N^{o} 1 / 2002$ - Diretrizes Operacionais para a Educação Básica nas Escolas do Campo (3/04/2002).

Leis de reformas de $1^{\circ}$ e $2^{\circ}$ Graus $n^{\circ} 5.692 / 71(11 / 08 / 1971)$.

Educação e Fronteiras On-Line, Dourados/MS, | v. 10, n. 30,| p. 136-152,| set /dez 2020 
Lei da reforma universitária n. $^{\circ}$ 5.540/68 (28/11/1968).

CALDART, Roseli Salete. Pedagogia do campo: sem terra. São Paulo. Expressão Popular, 2004.

Caminho para transformação da escola 2: agricultura camponesa, educação politécnica e escolas do campo. São Paulo. Expressão Popular, 2015.

Caminho para transformação da escola 4: trabalho, agroecologia e estudo nas escolas do campo. São Paulo. Expressão Popular, 2017.

FREITAS, Luiz Carlos de. A reforma empresarial da educação: nova direita, velhas ideias. São Paulo. Expressão Popular, 2018.

FRIGOTTO, Gaudêncio. CIAVATTA, Maria. Teoria e educação no labirinto no capital. São Paulo. Expressão Popular, 2016.

LUCKESI. Cipriano Carlos. Filosofia da educação. São Paulo: Cortez, 2017.

MOLINA, Mônica Castagna. Contribuições das licenciaturas em educação do campo para as políticas de formação de educadores. Educ. Soc., Campinas, v. 38, n.. 140, p.587-609, jul.-set., 2017.

MOREIRA, Antonio Flavio Barbosa. Currículos e programas no Brasil (Magistério: formação e trabalho pedagógico). Campinas - SP. Papirus Editora, 2014.

PERONI, Vera Marial Vidal. LIMA, Paula Valim de. KADER, Carolina Rosa. (Org.) Redefinições das fronteiras entre o público $e$ o privado: implicações para a democratização da educação. São Leopoldo-Oikos, 2018.

SAVIANI, Dermeval. Escola e democracia. Campinas, SP. Autores Associados, 2018. 
SILVA, Maria do Socorro. 50 Anos da CONTAG: fortalecendo o movimento sindical para melhorar a qualidade de vida no campo. Brasília-DF, 2013.

SILVEIRA, Ana Paula de Carvalho. SANTOS, Taís Conceição dos. CHRISPINO, Álvaro. Uma Análise do Conceito de Interdisciplinaridade no Ensino CTS Brasileiro. Revista Educação e Fronteiras On-Line. Dossiê "Educação ciência-tecnologiasociedade-ambiente: diálogos e caminhos para a inter e a transdisciplinaridade". Dourados/MS. v. 9, n. 25, 2019.

TROQUEZ, Marta Coelho Castro. Currículo e materiais didáticos para a educação escolar indígena no Brasil. Revista Educação e Fronteiras On-Line - Dossiê "Educação ciência-tecnologia-sociedade-ambiente: diálogos e caminhos para a inter e a transdisciplinaridade". Dourados/MS, v.9, n.25, p.166-182, jan./abr. 2019.

Recebido: $20 / 05 / 2020$

Aprovado: 20/07/2020 